\title{
La industria turística del Distrito Federal: de las debilidades a las fortalezas
}

\section{Maribel Espinosa Castillo*}

\section{Resumen}

Este trabajo intenta hacer una reflexión y una propuesta de cómo identificar, clasificar y analizar las actividades básicas y complementarias para el consumo del turismo. Parte de una revisión de la industria en general, hace una conceptualización de la industria turística y aterriza en la del Distrito Federal; todo ello con el objetivo de ampliar el conocimiento referente a las diversas empresas que participan en la economía turística y poder opinar en el momento de la toma de decisiones sobre sus giros $y$ actividades básicas.

Palabras | Distrito Federal, actividades turísticas, industria mexicana, CLAVE industria turística, sector servicios.

*Instituto Politécnico Nacional, Escuela Superior de Turismo / escasmar@hotmail.com / mespinosac@ipn.mx 


\section{Introducción}

En los últimos años, la actividad económica vinculada al turismo ha crecido rápidamente. Para el 2002, se logró un récord histórico de captación de divisas, que la colocó en el tercer lugar como actividad generadora de divisas después del petróleo y las exportaciones manufactureras (Presidencia de la República, 2003). La diversidad y la magnitud de lo turístico son tales que los datos oficiales respecto a su comportamiento no guardan homogeneidad en los indicadores analizados y no permiten distinguir a los sujetos y los hechos que intervienen en su proceso.

Identificar la estructura turística, su naturaleza, sus giros y su funcionamiento, entre otros aspectos, podría ayudar a precisar las fortalezas y debilidades de sus empresas. La política de modernización, mediante el programa Moderniza, sería más útil si sus acciones se focalizaran a empresa específicamente de servicio al turista; los programas de promoción turística podrían extenderse a las micro, pequeñas ymedianas empresas (mipymes) turísticas a fin de fortalecer la base de su economía o podrían ampliarse los apoyos financieros de la Secretaría de Economía a las empresas complementarias para consolidar la economía turística.

Por tal motivo, es importante conocer la naturaleza de la llamada industria turística a partir de un acercamiento a su composición, estructura y funcionamiento, la variedad de giros que abarca, las empresas que generan la mayor cantidad de empleos y aquéllas casi desconocidas que requieren promoverse, para definir el camino que deberá tomar la política gubernamental. De ahí que el objetivo del presente documento sea mostrar brevemente la dimensión de esta industria, atendiendo a la necesidad de información para la toma de decisiones de la política turística nacional, y a las exigencias de competitividad y modernización del mercado global.

\section{Antecedentes}

Las reflexiones de este texto parten de un proyecto denominado El Papel de la Industria Turística en la Dinámica Económico-Social: Caso Distrito Federal, realizado durante 2007, con el auspicio del Instituto Politécnico Nacional, y que representa una vertiente de un programa general de trabajo de quien suscribe, que versa sobre la caracterización y el análisis de la actividad turística en 
el Distrito Federal, que busca identificar sus fortalezas y debilidades, e indicar un camino para su desarrollo.

\section{Metodología}

Frente a la necesidad de información y a lo limitado de las estadísticas que ofrecen las instancias gubernamentales y académicas para precisar y mostrar los elementos de la industria turística, se decidió identificar y explicar la coceptualización de la industria turística, y a partir de eso discurrir sobre sus fortalezas y debilidades.

Se efectuó investigación bibliográfica, que partió del conocimiento de la industria en general, para llegar a la industria que abarca a diversas actividades que tienen como usuarios a los turistas. En ese marco, primero se puntualizaron las actividades turísticas dentro del grueso de los sectores y ramas de los censos económicos, después se distinguieron las principales actividades destinadas al turismo en los ámbitos nacional e internacional,y se concluyó comparando el turismo nacional con el primer mercado del país: el Distrito Federal.

\section{La industria mexicana y la industria turística}

Una cara del desarrollo de la nación puede verse en sus estadísticas de productividad, de ahí la importancia de conocer las estadísticas de los sectores y ramas de la economía. Al respecto, el sector primario, que involucra la agricultura, la silvicultura, las actividades forestales y la pesca, se ha visto muy afectado en los últimos años por las importaciones de alimentos y el retiro de los apoyos gubernamentales a los productores del campo, por lo cual el crecimiento de su producto interno bruto (PIB) para 2006 fue de $4.8 \%$. El sector secundario, o sea el industrial, conformado por la minería, la manufactura, la construcción, la electricidad, el agua y el gas, es el más dinámico, y alcanzó un PIB de 5\% para el mismo año. Finalmente, el sector servicios, que incluye las actividades comerciales, hoteleras y de restaurantes; transportes; comunicaciones; y servicios fiancieros, personales, comunales y sociales; tuvo un incremento de $4.9 \%$. Si bien podría aducirse un crecimiento uniforme del PIB en los tres sectores de la producción, en cada uno de ellos existen consideraciones especiales (INEGI, 2007). 
A partir de la entrada en vigor del capítulo agrícola del Tratado de Libre Comercio de América del Norte (TLCAN) en enero de 2008, la expansión del sector primario se considera en peligro, ya que la entrada de maíz y frijol importado impacta de manera directa al agro mexicano. El sector secundario, pero en especial las manufacturas, se ven seriamente afectadas por aquellas provenientes de países asiáticos, cuya variedad desplaza a las nacionales. Por último, en el sector servicios no todos los giros se han comportado igual, y son los servicios comerciales, de hoteles y restaurantes los que han experimentado un crecimiento destacado, pasando de I.5\% del PIB en 2003, a 3.7\% para 2006 (INEGI, 2007).

En ese sentido, en 2003 las actividades de uso del turismo tuvieron una participación preponderante: representaron $9.3 \%$ de la actividad económica del país y contribuyeron en $9.5 \%$ en la generación de empleos, es decir, de 3005 I57unidades económicas que el Instituto Nacional de Estadística, Geografía e Informática (INEGI) reportó en activo, 278439 las consideró turísticas;y del 6239536 personas ocupadas en el país, manifestó que I 536 566 trabajaban en el sector turismo (Sectur, 2006).

Con esto se evidencia la trascendencia del papel del sector turístico dentro de la economía nacional, pues más de la mitad de la producción del sector terciario proviene de él. Sin embargo, no se encuentra información que hable del tratamiento particulary delimitado que deben tener las actividades de uso de los turistas respecto a las actividades económicas en general.

Muchos de los registros oficiales y bancos de datos que señalan "la actividad económica turística" se refieren a aquella registrada en los hoteles, restaurantes o transportes, y quedan fuera otras, como la de guías de turistas o la venta de artesanías.Además, debe considerarse que muchas empresas turísticas son pequeñas y medianas, y que en ocasiones no se encuentran registradas ante las instancias hacendarias y fiscales, por lo tanto no proporcionan sus datos a las entidades gubernamentales encargadas de generar los registros económicos; esa situación se vuelve significativa cuando $99.4 \%$ de las empresas turísticas son micro, pequeñas y medianas (Sectur y Cestur, 2006: 6), y son las que cubren el mercado nacional.

En estas circunstancias, cabe preguntarse ¿cuáles empresas forman parte de la industria turística? Ya ha habido algunos esfuerzos por conceptualizarla, entre ellos el de Mario Rodríguez, quien la define como: 
Una industria terciaria o de servicios, tanto públicos como privados, referidos fundamentalmente al alojamiento y alimentación, y vinculados a las agencias de viajes, al transporte de pasajeros, a los guías de turistas, a los conductores de grupos; complementados por servicios de recreación y venta de productos típicos y artesanales. Todos estos servicios se apoyan, a su vez, en otros y en los bienes que producen las industrias extractivas y de trasformación [1982: 8].

Por su parte, Naciones Unidas señala que la industria turística es: "El conjunto de las actividades industriales y comerciales que producen bienes $y$ servicios consumidos total o parcialmente por visitantes extranjeros o por turistas nacionales" (cit. en Figuerola, 1985: 18).

De esta manera, la industria turística se refiere a las actividades económicas realizadas ex profeso para el consumo de los visitantes, o actividades de otros sectores económicos pero que son consumidas por los turistas.

Empero, al intentar identificar las actividades turísticas dentro de los registros gubernamentales, se encontró que las instancias que ofrecían los datos más confiables no coincidían en el tipo de giros considerados para uso del turista. Para el INEGI -órgano de generación y concentración de datos sobre la actividad económica y social del país-, la actividad turística no se sitúa en un rubro independiente dentro de las actividades económicas en general.

Los datos que ofrece el Instituto muestran el comportamiento económico de las variables más importantes por giros, entre las que destacan: unidades económicas, personal ocupado, total de remuneraciones, producción bruta total, consumo intermedio, valor agregado censal bruto, formación bruta de capital fijo y total de activos fijos, entre otros. Cabe apuntar que el INEGI da un tratamiento especial y amplio a las actividades de hospedaje en sus diversas modalidades: hoteles, moteles, campamentos, albergues, pensiones y casas de huéspedes; no obstante, la información sigue quedando limitada a determinados giros, lo cual no ayuda a tener un diagnóstico integral de los giros involucrados en la actividad turística.

Por otro lado, la Secretaría de Turismo (Sectur), como otro gran generador de datos, organiza, administra y analiza la información de ciertos giros de uso del turista: hoteles, restaurantes, aerolíneas, cruceros, agencias de viajes, guías de turistas, arrendadoras de autos, centros de convenciones y marinas. Entre los factores analizados, observamos los referentes a la cantidad de movimientos de personas, número de unidades económicas, personal ocupado, 
La industria turística

del Distrito Federal

individuos que practican turismo fronterizo y receptivo, llegadas y salidas por vía aérea y número de excursiones. Respecto a las variables relativas a los efectos económicos de esos movimientos se dispone de datos sobre el PIB, la balanza de pagos, la inversión extranjera y el gasto promedio. En cuanto al origen-destino de los viajeros se encuentran: origen de los viajeros, lugar de procedencia, centros turísticos visitados (museos, zonas arqueológicas y balnearios), entre otras.

La información que se tiene de las actividades turísticas no es homogénea, ya que mientras se dedica mucho tiempo y espacio a analizar vuelos y estadías dentro de la industria hotelera, es mínimo lo que se registra sobre parques turísticos o centros de convenciones. Para 2003, el INEGI registró 42 organizadores de convenciones y ferias a nivel nacional, lo cual resulta poco confiable por la cantidad de ferias y eventos locales, municipales $y$ regionales en el país. De ahí la necesidad de enlistar, clasificar y agrupar las actividades económicas de lo que se considera la industria turística o de las actividades destinadas al consumo del turista.

Se advirtió que no existe una identificación única de las actividades orientadas al turismo, ni una identificación homogénea entre giros analizados por las dos instancias gubernamentales INEGI-Sectur, ni tampoco un seguimiento de las variables económicas examinadas. Tampoco se halló una base de datos que permitiera distinguir las actividades propias de la industria y conocer su naturaleza. Si bien en la actualidad son limitados los análisis de la actividad turística, sería mucho más útil que ellos fueran sobre datos confiables y desagregados en indicadores consensuados que ayudaran a estudiar el comportamiento del fenómeno desde diversas perspectivas pero sobre una misma base de datos. Las investigaciones que se hacen de la actividad turística resultan, en consecuencia, muy limitadas y débiles, solamente reproducibles con los mismos indicadores y fuentes.

No deben confundirse las actividades económicas con los atractivos turísticos, no puede considerarse a la mayoría de los museos y zonas arqueológicas como empresas, pues ellos forman parte de los atractivos determinados por la Sectur, muchos de los cuales están a resguardo del Instituto Nacional de Antropología e Historia, de la Secretaría de Medio Ambiente y Recursos Naturales, de los gobiernos de los estados o municipios, de asociaciones civiles, o de sociedades de solidaridad social, comuneros o ejidatarios. Aunque en buena parte de los lugares turísticos se cobra la entrada al turista, en general el costo es destinado a su mantenimiento o al pago de nómina de los empleados, 
y sólo en algunas excepciones representa una ganancia para la entidad que los administra.

Aunado a lo anterior, se observó que las estadísticas históricas del rubro no pueden referirse ni compararse en su evolución histórica. La clasificación de las actividades económicas para México cambió a partir de los compromisos del país con el exterior, los censos económicos de 1999 y 2004 fueron elaborados con el Sistema de Clasificación Industrial de América del Norte (SCIAN), mientras que los censos anteriores fueron realizados con base en la Clasificación Mexicana de Actividades y Productos (CMAP). Tratar de verificar la evolución de una de las actividades económicas de uso de los turistas a través del tiempo implicaría iniciar el seguimiento en los dos sistemas de clasificación -SCIAN y CMAP-, los cuales tienen obviamente una categorización distinta.

Por otro lado, en el análisis de la industria turística debe tomarse en cuenta que la diversidad de actividades económicas, servicios y productos considerados turísticos no son de uso exclusivo del turista, y por ello debe tenerse un especial manejo de los datos, diferenciando las actividades que son exclusivas o básicas para la existencia del turismo, de aquellas que son complementarias, facilitan, permiten o generan un valor agregado para el turista en la práctica. Con esta premisa como marco, y con base en las actividades censadas por el INEGI, las examinadas por la Sectur y las identificadas por el Gobierno de la Ciudad de México, se propone una clasificación de las actividades que pueden ser consideradas integrantes de la economía turística, pero que a su vez, algunas de ellas, son parte de la estructura de la ciudad y no dependen de los turistas.

En el cuadro I se muestran las actividades básicas y complementarias para la práctica turística, donde pueden distinguirse aquellas reconocidas por las diversas instancias de gobierno y la especificidad en su tratamiento o desglose como actividad económica. De tal modo, las actividades económicas para el consumo del turismo se consideran básicas, y aquéllas de uso de los citadinos y turistas son complementarias. Entre las básicas están: venta de artesanías; transporte aéreo regular o de líneas aéreas; transporte turístico por tierra; transporte turístico por agua; agencias de viajes en todas sus formas, agencias de excursiones, guías y paquetes turísticos; marinas, hoteles, cabañas y villas, tiempos compartidos, departamentos y casas para turistas. El resto son complementarias a la actividad turística, y no excluyentes de la economía de las ciudades o regiones (véase cuadro I). 
La industria turística

del Distrito Federal

CuAdRo I.ACTIVIDADES ECONÓMICAS IDENTIFICADAS DENTRO DE LA INDUSTRIA TURÍSTICA

Actividades económicas

Actividades económicas usadas por el turismo de de uso urbano y turís-

$B, C^{*}$ acuerdo con el INEGI y la SECTUR tico de acuerdo con el Gobierno Cd. de México

Comercios de venta de artesanías

Transporte aéreo regular o líneas aéreas

Transporte aéreo no regular

Transporte turístico por tierra

Transporte turístico por agua (cruceros)

Arrendadora de autos

Casas de cambio

Centros cambiarios

Agencias de viajes: touroperadoras,

Agencias mayoristas, agencias minoristas y agencias especializadas

Organización de excursiones y paquetes turísticos para agencias de viajes (guías de turistas)

Otros servicios de reservaciones

Organizadores de convenciones y ferias comerciales e industriales

Parques del sector privado con instalaciones recreativas (asociaciones, organismos o empresas que ofertan actividades turísticas en áreas naturales)

Campos de golf

Marinas

Balnearios del sector privado $\quad B / C$

Otros servicios recreativos prestados por el sector privado (spas)
Campos de golf

C

B

Artesanías

Transporte aéreo regular o líneas aéreas

Transporte aéreo no regular

C

Transporte turístico por tierra

Arrendadora de autos C

Casas de cambio

C

C

Agencias de viajes

C

C comerciales $\mathrm{e}$

industriales

Parques del sector

privado con

instalaciones recreativas

$\mathrm{B} / \mathrm{C}$

C 
CUAdRo I.ACTIVIDADES ECONÓMICAS IDENTIFICADAS DENTRO DE LA INDUSTRIA TURÍSTICA (Continuación)

\begin{tabular}{|c|c|c|}
\hline $\begin{array}{l}\text { Actividades económicas usadas por el turismo de } \\
\text { acuerdo con el INEGI y la SECTUR }\end{array}$ & $\begin{array}{l}\text { Actividades económicas } \\
\text { de uso urbano y turís- } \\
\text { tico de acuerdo con el } \\
\text { Gobierno Cd. México }\end{array}$ & $\begin{array}{l}\mathrm{B}, \mathrm{C}^{*} \\
\mathrm{~B} / \mathrm{C}\end{array}$ \\
\hline Hoteles con otros servicios integrados & Hoteles & B \\
\hline Hoteles sin otros servicios integrados & & B \\
\hline Moteles & & C \\
\hline Cabañas, villas y similares & & B \\
\hline Campamentos y albergues recreativos & & C \\
\hline Pensiones y casas de huéspedes & & C \\
\hline $\begin{array}{l}\text { Departamentos y casas amueblados con } \\
\text { servicios de hotelería (tiempos compartidos) }\end{array}$ & & B \\
\hline Restaurantes-bar con servicio de meseros & Restaurantes & $\mathrm{B} / \mathrm{C}$ \\
\hline $\begin{array}{l}\text { Restaurantes sin bar y con servicio de meseros } \\
\text { (de comida internacional) }\end{array}$ & & $\mathrm{B} / \mathrm{C}$ \\
\hline Restaurantes de autoservicio & $\begin{array}{l}\text { Restaurantes de } \\
\text { autoservicio }\end{array}$ & C \\
\hline Restaurantes de comida para llevar & $\begin{array}{l}\text { Restaurantes de } \\
\text { comida para llevar }\end{array}$ & C \\
\hline $\begin{array}{l}\text { Centros nocturnos, discotecas y similares, } \\
\text { cafeterías }\end{array}$ & $\begin{array}{l}\text { Centros nocturnos, } \\
\text { discotecas y similares, } \\
\text { cafeterías }\end{array}$ & $C$ \\
\hline Bares y cantinas & Bares y cantinas & $C$ \\
\hline
\end{tabular}

El gobierno del Distrito Federal agrupa como hoteles la diversidad de hospedajes, al igual que las agencias de viajes y los restaurantes. Asimismo no se toman en cuenta las actividades que requieren agua para llevarse a cabo, como las marinas o los transportes turísticos acuáticos, puesto que no 
La industria turística

del Distrito Federal

existen tales recursos en la entidad. De estas actividades básicas y complementarias se concluye que las preponderantemente turísticas son las de venta de artesanías, del transporte, agencias de viajes, de hospedaje y de servicios de alimentación en restaurantes.

Hay que pensar que las actividades económicas destinadas al turismo también son consumidas por las personas que viven donde se localizan los atractivos motivos del desplazamiento; hoteles, restaurantes y otros servicios son consumidos por la población local; entonces, no puede reconocerse cuando un usuario es turista y cuando no. Este hecho representa una de las debilidades al analizar el fenómeno turístico, ya que los trabajos que pretenden ser objetivos y metódicos deben tener bien identificado su objeto de estudio. He aquí que una de las dificultades de la investigación turística, particularmente de la teoría del turismo, sea identificar con claridad quiénes son sus actores u objetos de análisis y sus espacios.

Si bien en sentido estricto no existe el "sector turístico", ni la industria del turismo como una actividad mecanizada generadora de productos, sí existe un grupo de actividades económicas que, basado en atractivos tanto naturales como culturales, planea, administra y vende mercancías para el turista, y que es a lo que llamamos industria turística.

\section{La industria turística en el Distrito Federal}

En lo antes expuesto queda determinada la estructura económica por sectores, que es la base para comprender la dinámica turística. La razón por la que este estudio se enfoca en el Distrito Federal es que la ciudad represen ta el centro del poder económico y político,y en él se han concentrado históricamente las actividades de carácter turístico.

Cuando se analizó el número de llegadas de turistas en el nivel nacional en 2006, descubrimos que al Distrito Federal arribaron 10296 329, lo cual representó $13.7 \%$ de todas las llegadas de turistas nacionales e internacionales, por arriba de Quintana Roo, que tuvo 6 I0I 390 (8.I\% de llegadas); de Guerrero, con 5818100 llegadas (7.7\%);y de Jalisco, con 5452893 (7.2\%) (Sectur, 2006). Estos datos muestran la supremacía del Distrito Federal como el primer destino turístico tanto nacional como internacional, y por ello la necesidad de conocer su comportamiento. 
A lo largo de la historia, la Ciudad de México ha resguardado edificios y actividades, expresión del desenvolvimiento cultural del país, y ha invertido enormes recursos en infraestructura y equipamiento urbano, que la hacen un espacio accesible y atractivo. Museos, zonas arqueológicas, iglesias y catedrales, parques recreativos, establecimientos comerciales y obras arquitectónicas de personalidades internacionales son algunos motivos de los desplazamientos a la ciudad.

Frente al reto de reconocer lo que es la industria turística del Distrito Federal, los cuestionamientos que guiaron este trabajo fueron: ¿Dónde está localizada la industria turística en el Distrito Federal? ¿Cuál es su estructura básica? ¿Cuáles son sus retos frente a la competencia global?

Si bien en todo el Distrito Federal se localizan empresas que ofrecen servicios turísticos, primero se ubicaron en el primer cuadro de la ciudad, y posteriormente en delegaciones con altos niveles de infraestructura y equipamiento urbano al sur de la capital. Así, de $355 \mathrm{I}$ establecimientos turísticos, 2550 (72.2\%) se asentaron en las delegaciones Cuauhtémoc, Benito

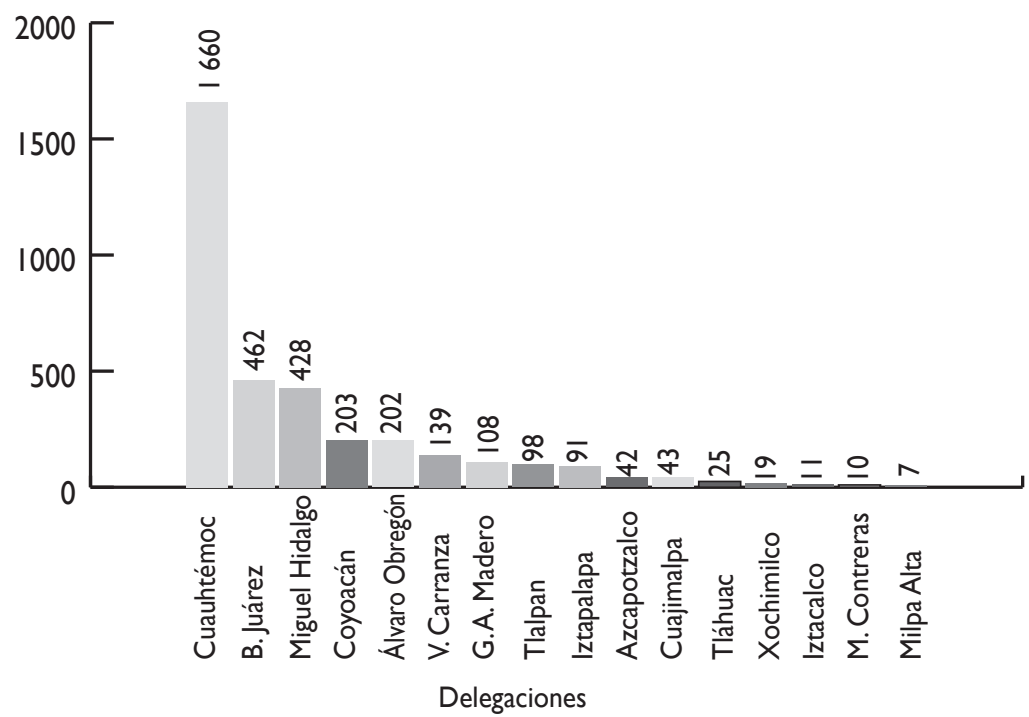

Fuente: Elaboración propia con base en la Secretaría de Turismo de la Ciudad de México, 2006.

Gráfica I. Localización de los establecimientos turísticos en el Distrito Federal 
Juárez y Miguel Hidalgo, es decir, en el Centro Histórico de la Ciudad de México, destacando también las delegaciones Coyoacán y Álvaro Obregón con 405 empresas (I I.3\%) (véase gráfica I).

La localización de las empresas es comprensible si se considera que el centro de la ciudad concentra los edificios históricos más importantes de la nación y una magnífica infraestructura y equipamiento urbano, además de ser el espacio del poder económico y político del país.

A partir del año 2000, el gobierno del Distrito Federal inició diversos programas de desarrollo; se renovó la infraestructura de drenaje, electricidad, red de agua, cableado telefónico por tierra, alumbrado público y mobiliario e imagen urbanos, todo ello con el objetivo de rescatar su Centro Histórico y apoyar las condiciones generales de producción de sus habitantes. Los más beneficiados con estas acciones fueron los empresarios del Centro Histórico, quienes atestiguaron la remodelación del centro de la ciudad, principal motivo del desplazamiento.

Durante muchos años la ciudad no fue atendida hasta que el jefe de Gobierno Andrés Manuel López Obrador le devolvió parte de su hermosura, fortaleció su economía en general y la economía turística en particular, además de favorecer a empresarios del centro.

Destacan también las delegaciones Coyoacán y Álvaro Obregón por la concentración de establecimientos turísticos; en estas delegaciones en los últimos años se han creado áreas comerciales y de servicios entre las que sobresale el centro histórico de Coyoacán y la zona comercial de Santa Fe como atractivos que originan los nuevos desplazamientos.

Por otro lado, al hacer una primera revisión de la industria turística, tanto en la esfera nacional como en el Distrito Federal, se evidenciaron similitudes destacando cuatro características. La primera tiene que ver con el comportamiento del giro de los restaurantes, que es el que más unidades económicas reporta. En el país se registraron 69853 unidades económicas entre las dos ramas, restaurantes con meseros y de comida para llevar, mientras que en el Distrito Federal se ubicaron 4383 establecimientos en las mismas ramas, lo cual significa que la ciudad concentra $6.2 \%$ de restaurantes. No hay que olvidar que los restaurantes son de uso tanto de los turistas como de la población local, y que son de los negocios de mayor éxito en cuanto a su apertura y permanencia. La industria de los alimentos es muy dinámica y flexible, relativamente requiere poca inversión, el equipo es fácil de adquirir 
Cuadro 2. Industria turística nacional y en el Distrito Federal

\begin{tabular}{|c|c|c|c|c|}
\hline \multirow[t]{2}{*}{$\begin{array}{l}\text { Actividades económicas usadas por } \\
\text { el turismo }\end{array}$} & \multicolumn{2}{|c|}{$\begin{array}{l}\text { Unidades } \\
\text { económicas }\end{array}$} & \multicolumn{2}{|c|}{$\begin{array}{l}\text { Personal } \\
\text { ocupado }\end{array}$} \\
\hline & Nac. & D. F. & Nac. & D. F. \\
\hline Comercios de venta de artesanías & 14999 & I 270 & 29740 & 2639 \\
\hline $\begin{array}{l}\text { Transporte aéreo regular o líneas } \\
\text { aéreas }\end{array}$ & 42 & 34 & 23560 & 22210 \\
\hline Transporte aéreo no regular & 137 & 19 & $2|3|$ & 423 \\
\hline Transporte turístico por tierra & I 079 & 98 & 10337 & 1300 \\
\hline $\begin{array}{l}\text { Transporte turístico por agua } \\
\text { (cruceros) }\end{array}$ & I 168 & 17 & 10637 & 1080 \\
\hline Otro transporte turístico & 0 & 0 & 25 & 0 \\
\hline Casas de cambio & 5 & 0 & $1|7|$ & 1223 \\
\hline Centros cambiarios & I 246 & 0 & 3927 & 181 \\
\hline $\begin{array}{l}\text { Agencias de viajes y servicios de } \\
\text { reservaciones }\end{array}$ & 4034 & 743 & 32032 & 9940 \\
\hline $\begin{array}{l}\text { Agencias de viajes: touroperadoras, } \\
\text { agencias mayoristas, agencias } \\
\text { minoristas y agencias especializadas }\end{array}$ & 3442 & 743 & $237 / 4$ & 9940 \\
\hline $\begin{array}{l}\text { Organización de excursiones y } \\
\text { paquetes turísticos para agencias de } \\
\text { viajes (guías de turistas) }\end{array}$ & 380 & 74 & 3156 & I 224 \\
\hline Otros servicios de reservaciones & 212 & 30 & 5162 & 347 \\
\hline $\begin{array}{l}\text { Organizadores de convenciones y } \\
\text { ferias comerciales e industriales }\end{array}$ & 42 & 18 & I 289 & 255 \\
\hline $\begin{array}{l}\text { Parques del sector privado con } \\
\text { instalaciones recreativas (asociacio- } \\
\text { nes, organismos o empresas que } \\
\text { ofertan actividades turísticas en } \\
\text { áreas naturales) }\end{array}$ & 2850 & 50 & 10385 & 814 \\
\hline $\begin{array}{l}\text { Parques del sector privado con } \\
\text { instalaciones recreativas }\end{array}$ & 79 & 0 & 5178 & 629 \\
\hline Otros servicios recreativos & 3312 & 118 & 22630 & I 400 \\
\hline
\end{tabular}


La industria turística

del Distrito Federal

Cuadro 2. Industria turística nacional y en el Distrito Federal

(Continuación)

\begin{tabular}{|c|c|c|c|c|}
\hline \multirow[t]{2}{*}{$\begin{array}{l}\text { Actividades económicas usadas por } \\
\text { el turismo }\end{array}$} & \multicolumn{2}{|c|}{$\begin{array}{l}\text { Unidades } \\
\text { económicas }\end{array}$} & \multicolumn{2}{|c|}{$\begin{array}{l}\text { Personal } \\
\text { ocupado }\end{array}$} \\
\hline & Nac. & D.F. & Nac. & D.F. \\
\hline Campos de golf & 25 & 0 & 1809 & 0 \\
\hline Marinas turísticas & 62 & 0 & 895 & 0 \\
\hline Balnearios del sector privado & 404 & 4 & 4740 & 19 \\
\hline $\begin{array}{l}\text { Otros servicios recreativos presta- } \\
\text { dos por el sector privado (spas) }\end{array}$ & 459 & 21 & 2576 & $|5|$ \\
\hline Hoteles, moteles y similares & II 344 & 626 & 236619 & 23037 \\
\hline $\begin{array}{l}\text { Hoteles con otros servicios } \\
\text { integrados }\end{array}$ & 2952 & 255 & 177760 & 18554 \\
\hline $\begin{array}{l}\text { Hoteles sin otros servicios } \\
\text { integrados }\end{array}$ & 6706 & 344 & 41247 & 3898 \\
\hline Moteles & 1388 & 27 & 15050 & 585 \\
\hline Cabañas, villas y similares & 298 & 0 & 2562 & 0 \\
\hline $\begin{array}{l}\text { Campamentos y albergues } \\
\text { recreativos }\end{array}$ & 64 & 0 & 1112 & 12 \\
\hline $\begin{array}{l}\text { Pensiones y casas de huéspedes y } \\
\text { departamentos y casas amueblados } \\
\text { con servicios de hotelería }\end{array}$ & 1569 & 55 & & 177 \\
\hline Pensiones y casas de huéspedes & I 475 & 55 & 4026 & 177 \\
\hline $\begin{array}{l}\text { Departamentos y casas amueblados } \\
\text { con servicios de hotelería (tiempos } \\
\text { compartidos) }\end{array}$ & 94 & 5 & 707 & 27 \\
\hline $\begin{array}{l}\text { Restaurantes con servicio de } \\
\text { meseros }\end{array}$ & 21035 & 2058 & 163270 & 31117 \\
\hline $\begin{array}{l}\text { Restaurantes-bar con servicio } \\
\text { de meseros }\end{array}$ & 6316 & 543 & 77312 & 16538 \\
\hline $\begin{array}{l}\text { Restaurantes sin bar y con servicio } \\
\text { de meseros (de comida internacional) }\end{array}$ & 14719 & 1515 & 85958 & 14579 \\
\hline Restaurantes de comida para llevar & 48818 & 2325 & $144 \mid 88$ & 9558 \\
\hline
\end{tabular}


Cuadro 2. Industria turística nacional y en el Distrito Federal

(Continuación)

\begin{tabular}{|c|c|c|c|c|}
\hline \multirow[t]{2}{*}{$\begin{array}{c}\text { Actividades económicas usadas por } \\
\text { el turismo }\end{array}$} & \multicolumn{2}{|c|}{$\begin{array}{l}\text { Unidades } \\
\text { económicas }\end{array}$} & \multicolumn{2}{|c|}{$\begin{array}{l}\text { Personal } \\
\text { ocupado }\end{array}$} \\
\hline & Nac. & D.F. & Nac. & D.F. \\
\hline Restaurantes de autoservicio & 28750 & 454 & 91463 & 6689 \\
\hline Restaurantes de comida para llevar & 20068 & 871 & 52725 & 2869 \\
\hline $\begin{array}{l}\text { Centros nocturnos, discotecas } \\
\text { y similares, cafeterías }\end{array}$ & 6004 & $|3|$ & 30984 & 1154 \\
\hline $\begin{array}{l}\text { Centros nocturnos, discotecas } \\
\text { y similares }\end{array}$ & 832 & 24 & 13049 & 521 \\
\hline Bares y cantinas & 4496 & 74 & 16383 & 530 \\
\hline Total & 278439 & 22671 & I 536566 & 242247 \\
\hline
\end{tabular}

Fuente: Elaboración propia con base en INEGI, 2004.

o es de propiedad familiar, los conocimientos para su procesamiento son de carácter social y personal, y en ella se generan productos de primera necesidad; de ahí que sus establecimientos se vean poco afectados por crisis económicas, sociales o financieras (véase cuadro 2).

La segunda característica resulta de analizar el conjunto de empleos generados en la industria turística. De un total de I 536566 empleos del sector servicios en el territorio nacional, las empresas de alimentos y hospedajes juntas ofrecen 543877 (35.4\% de los empleos del sector); en tanto en el Distrito Federal, de 242247 empleos reportados, los hoteles y restaurantes concentraron 63712 (26.3\% de las fuentes de trabajo del sector servicios en la esfera local). Sin embargo, estas empresas pueden todavía ocupar más personal, ya que en muchas de ellas, de manera señalada en los restaurantes, los empleados no están registrados ante las autoridades hacendarias, trabajan sólo por las propinas o tienen contratos cortos con empresas de diversa razón social, para no generar derechos ni obligaciones de la parte patronal.

Los empleos en la actividad turística tienen la desventaja de que son de temporada, es decir, se contratan en temporada de vacaciones. Muchos de quienes atienden los parques recreativos y balnearios o los guías de turistas tienen trabajo dos, tres o cuatro meses, y se ocupan en otras actividades o lugares el 
La industria turística

del Distrito Federal

resto del año. De igual manera, los puestos generados por las empresas de transportes aéreo o terrestre no son siempre los declarados; hay muchos de esos servicios que son concesionados a otras empresas, como el caso de servicios auxiliares (ASA) en los aeropuertos.

Además, debe tomarse con reservas el número de empleados existente al momento de censar, ya que ellos no necesariamente permanecieron en el trabajo al finalizar el año. La rotación de personal en las empresas turísticas es una de las causas de la baja calidad en la prestación de servicios. La preparación de los prestadores de servicios, la no rotación y la capacitación del personal son algunos elementos que permitirán a las empresas turísticas lograr la calidad en sus funciones. Esta circunstancia, comparada con la generación de empleos en la industria manufacturera, por ejemplo, muestra parte de sus debilidades. Aquello que permitirá fortalecer lo que se pretende consensuar como industria turística es el cuidado de la seguridad en el trabajo; la pertenencia a una firma o marca, donde los trabajadores se sientan miembros de esa gran familia que es la empresa; el incentivo institucional por el buen desempeño; la posibilidad de ascender en la escala laboral; y la capacita ción del personal que atiende al turismo.

La tercera característica que observamos se refiere a las artesanías. Dentro de las actividades de consumo de los turistas, destaca en los dos niveles de gobierno el comercio de artesanías al menudeo; en tanto en la República se tuvieron 14999 empresas, en el Distrito Federal el número corresponde a I 270 unidades (8.4\%). La venta de artesanías es uno de los negocios dirigidos de manera específica a los turistas: las creaciones artísticas, artesanales y bellas son parte de las ganancias culturales que obtienen las personas durante sus viajes. Las empresas de hospedaje, alimentación y agencias de viaje se han asumido por lo general como aquellas que implican actividades propiamente turísticas, mientras que a la elaboración y venta de artesanías no se le ha dado el lugar como actividad productiva concretamente turística.

Frente al turismo de sol y playa, las ferias comerciales, agropecuarias, religiosas o culturales y las fiestas patronales son poco apoyadas y casi inexistentes para los turistas. Impulsar su modernización y promoción podría diversificar la oferta turística y los motivos de desplazamiento. Habrá que poner mucha creatividad, innovación y trabajo para formar productos turísticos y con ello fortalecer al turismo. 
En la cuarta y última característica destaca el personal del transporte aéreo regular, que en la esfera nacional asciende a 23560 empleados, y en la local, a 22 2I0. La concentración de las actividades económicas, políticas y sociales en el Distrito Federal se hace patente en la localización de estos empleos, ya que $94.2 \%$ de los puestos generados en esta rama se declaran en el Distrito Federal. Las aerolíneas Mexicana y Aeroméxico ofrecen trabajo a cerca de 14000 personas, es decir a $59.4 \%$ del personal del ramo (después de la venta de Aeroméxico al grupo Banamex y otros accionistas, quizá disminuya el número de empleados).

Al hablar de la industria turística estamos tomando en cuenta sólo aquella registrada ante una instancia gubernamental como el INEGI; sin embargo, existen infinidad de negocios, pequeños establecimientos y personas que atienden a los turistas y que no se registran como actividades de esta industria. En un estudio de 2006 se encontró que $47.6 \%$ de los negocios visitadas por el equipo de trabajo tienen más de diez años, esto es, que la mitad de las empresas estaban consolidadas, y casi la otra mitad en vías de estarlo. Asimismo, esas empresas identificaron con claridad los procesos administrativos a los que se debían ceñir, sea de administración científica, estratégica o a través del desarrollo organizacional. Muchos de estos negocios corresponden a $99.4 \%$ de las mipymes que existen según la Sectur y el Cestur (2006). De esta manera, la aglutinación de las actividades turísticas en el Distrito Federal se observa no sólo en el $13.7 \%$ de turismo que recibe ni en el predominio de actividades económicas de hospedaje y restaurante, sino en la concentración estratégica de las actividades de transportación aérea, que poco a poco se van descentralizando.

El proceso de modernización y socialización de los procedimientos de administración empresarial para la eficiencia de los negocios en general, ha disminuido el número de aquellos antes llamados familiares.

La modernización promovida por la Sectur a partir del 2002, mediante el programa Moderniza, es superada por la socialización de elementos globales en casi todos los negocios y empresas del país. A partir de la incorporación de las tecnologías de información y comunicación al turismo, el sector se ha dinamizado. En los primeros años de la Internet en México, se pensó que con esta tecnología se vería desaparecer a las agencias de viajes, empero, la nueva dinámica de comercialización y venta de productos y servicios turísticos por Internet ha conducido a un modo diferente de compra; si bien Internet ha 
cambiado la forma de planear y elegir un viaje y servicios complementarios, las agencias se han adaptado a las nuevas herramientas tecnológicas. La Internet permite que el futuro viajero tenga una experiencia más al identificar y elegir lugares, actividades y vivencias; no obstante, por seguridad o por cultura comercial, los usuarios contactan por teléfono o en persona a los agentes con el fin de confirmar sus viajes y la seguridad de su compra.

Para cualquier empresa es importante insertarse a la globalización, pero para las que se dedican al turismo es un requisito que determina su existencia o su extinción. Las empresas saben que tienen que integrar requerimientos tecnológicos e informáticos para poder competir. De acuerdo con la observación realizada en algunas empresas turísticas del Distrito Federal, por lo menos la mitad de ellas ofrecía sus servicios en la red electrónica, lo cual es comparable a 4.74, sobre diez de calificación que tienen México y Latinoamérica como capacidad de adopción tecnológica, según la Sectur y el Cestur (2006).

La economía y la vida cotidiana se han visto desfasadas, ya que es más rápido el desarrollo tecnológico que el tiempo que toma adaptarse a él. Las tecnologías de información y comunicación han dinamizado los procesos de administración, comercialización y venta de servicios turísticos, y por ello las instancias gubernamentales tienen la responsabilidad de dirigir y encaminar a las empresas en su inserción en los nuevos procesos y mercados.

\section{Conclusiones}

Si bien es cierto que el conjunto de las actividades de uso de los turistas no constituye en estricto sentido un sector o un atractivo, sí forma parte de una serie de productos y servicios que de manera didáctica hemos denominado aquí industria turística. Asimismo, se deben tener claramente identificadas qué actividades (por giro, rama o actividad) son turísticas, a fin de fortalecer los marcos de referencia y objetos de estudio del turismo.

Una de las debilidades de esta industria ha sido enfocar los apoyos a ramas o giros específicos, como los de turismo de sol y playa, y no diversificar las promociones y patrocinios económicos hacia aquellas empresas, fundamentalmente pequeñas, que mantienen al turismo nacional y local, y que asisten a ferias, fiestas patronales, parques recreativos o áreas naturales, entre otras cosas. La política turística deberá centrarse en las debilidades de las empresas con objeto de incrementar y consolidar la oferta de sus servicios. 
La multiplicidad de negocios que participa en la industria turística necesita políticas particulares:hay ramas o giros mucho más numerosos, como la industria de los alimentos y alojamiento, de los cuales su atención y fortalecimiento forman parte de la política económica nacional, mientras que otros como los balnearios o los cruceros requieren políticas económicas especiales que no desincentiven la afluencia de turistas, pero que les permitan crecer y afianzarse. Por ello, para la toma de decisiones en política gubernamental, las empresas turísticas tienen que ser conocidas en su naturaleza, estructura y funcionamiento.

El Distrito Federal sigue concentrando población, actividades económicas y poderes, $y$ más recientemente se ha visto remozado y embellecido, con lo cual se han incrementado las razones para que lo visiten, de ahí que saber qué requieren las diferentes ramas y giros turísticos es fundamental.

Frente a la competencia global, la industria turística de México en general y la del Distrito Federal en particular tienen que modernizarse, no únicamente haciendo sus procesos administrativos más organizados y eficientes, sino definiendo su camino en función de la calidad del servicio que ofrecen (precio, trato humano y sustentabilidad), y de las directrices económicas y tecnológicas que define el mercado mundial; todo ello se podrá lograr si se entiende puntualmente su estructura y funcionamiento.

En el análisis de la industria turística, distinguir qué empresas ofrecen servicios al turista permitirá destinarles los apoyos económicos de la Secretaría de Economía, el programa Moderniza o de la política de la Secretaría de Turismo, para elevar su competitividad, sobre todo frente al reto que impone el mercado internacional.

\section{FUENTES CONSULTADAS}

Figuerola, Manuel (1985). Teoría económica del turismo. Madrid:Alianza Editorial. INEGI (2004). Estadísticas de turismo con base en los resultados de los censos económicos 2004. México: Instituto Nacional de Estadística, Geografía e Informática.

(2007). Producto interno bruto trimestral según gran división. Sistema de cuentas nacionales de México. [Base de datos en línea]. México: Disponible en: www.inegi.gob.mx/est/contenidos/español/ritinas/ept. asp?t=agr0 I \&s=est [2007, 29 de agosto]. 
Presidencia de la República (2003). "Récord histórico en la captación de divisas por turismo extranjero en 2002: 8858 millones de dólares". Las Buenas Noticias también son Noticia, México, II de febrero de 2003. Disponible en <http://fox.presidencia.gob.mx/buenasnoticias/ ?contenido $=4456 \&$ pagina $=$ I \&fecha_desde_year $=2003 \& f e c h a \_h a s-$ ta_year $=2003 \&$ palabras $=$ record + hist $\% F 3$ rico+en+la+captaci\%F3n+de+divisas>, consultada el 30 de agosto de 2007.

Rodríguez López, Mario (1982). Teoría general del turismo. Cincinnati: SouthWestern.

Sectur (2006). Compendio estadístico del turismo en México 2006 (Datos del 2003). México: Secretaría de Turismo.

Sectur y Cestur (2006). "Impacto de las tecnologías de información en las pequeñas y medianas empresas turísticas”. Reporte Ejecutivo. México: Secretaría de Turismo/Centro de Estudios Superiores en Turismo.

Secretaría de Turismo de la Ciudad de México. (2006). "Prestadores de servicios"[Base de datos de prestadores de servicios]. México: Disponible en http://www.mexicocity.gob.mx/prestadores. php?cat $=4 \mid$ 300\&sub=0 [2006, 25 de marzo]. 